\title{
TRANSPARENCY IN MONETARY POLICY, SIGNALING, AND HETEROGENEOUS INFORMATION
}

\author{
VOLKER HAHN \\ University of Konstanz
}

\begin{abstract}
We examine the welfare implications of two types of central-bank transparency: the publication of the information underlying the central bank's decision (decision transparency) and the release of the information that the central bank observes afterwards (postdecision transparency). Decision transparency does not make the public better informed in equilibrium. Even so, it may be socially desirable because it eliminates harmful equilibria. Postdecision transparency has ambiguous effects. It reduces output variance and the distortions stemming from heterogeneous information. In this sense, it can be used as a substitute for monetary policy. However, postdecision transparency generally raises the variance of inflation. We argue that a conflict of interests may arise between society and the central bank with regard to transparency.
\end{abstract}

Keywords: Monetary Policy, Transparency, Signaling, Heterogeneous Information

[M]onetary policy is—at its heart—-the problem of managing and coordinating expectations.

-Morris and Shin (2008, p. 89) on the modern "expectationalist" view of monetary policy. ${ }^{1}$

\section{INTRODUCTION}

In line with the view of Morris and Shin, central banks' approaches to communication have been undergoing a paradigm shift toward ever-higher levels of transparency. Dincer and Eichengreen (2010) find that, among the 100 central banks surveyed by them, no central bank was less transparent in 2006 than in 1998, and 90 central banks had a higher degree of transparency. In this paper, we examine whether this development is socially desirable. In doing so, we allow for two different interpretations of "managing and coordinating expectations." First, if the views of the private sector about economic fundamentals differ, communication may align the public's diverse views about the economy. Second, in the presence

I would like to thank Hans Gersbach, Martin Scheffel, Elisabeth Schulte, seminar participants in Zurich, members of the annual meeting of the Verein für Socialpolitik in 2010, an anonymous referee, and an associate editor for many valuable comments and suggestions. Address correspondence to: Volker Hahn, Department of Economics, University of Konstanz, Box 143, 78457 Konstanz, Germany; e-mail: volker.hahn@uni-konstanz.de. 
of multiple equilibria, central-bank communication may allow coordination on a particular equilibrium. ${ }^{2}$

We evaluate the implications that these two forms of coordination have for welfare, studying the strategic interaction between a central bank that is imperfectly informed about demand shocks and a multitude of firms with heterogeneous information about these disturbances. The central bank can achieve the two different forms of coordination by two different forms of transparency. First, the central bank can publish the information underlying its decision. We show that transparency in this respect, which we henceforth refer to as "decision transparency," will not make firms better informed in equilibrium because they can infer the central bank's private information from observing monetary policy anyway. Decision transparency will be desirable nonetheless, as it facilitates coordination on a socially beneficial equilibrium.

Second, the central bank can publish the information it has received after locking in a particular course of monetary policy. We label this communication practice "postdecision transparency." 3 Postdecision transparency enables the other form of coordination considered in this paper: It tends to align diverse private-sector forecasts. Whether this type of coordination is beneficial is less clear-cut. First, postdecision transparency reduces the distortions arising from heterogeneous information; this is socially desirable. Second, postdecision transparency generally reduces output variance; in this sense, communication serves as a substitute for conventional policy measures. Third, postdecision transparency increases social losses in terms of inflation variance. This is a consequence of the observation that publishing information about demand shocks widens the gap between the prices chosen by the firms that use outdated information and the prices of the other firms. On balance, postdecision transparency will be desirable from a social point of view if society values output stabilization sufficiently highly.

The paper is organized as follows. We survey the related literature in Section 2. In Section 3 we lay out our model. We derive the solution if the central bank publishes the information underlying its decision in Section 4. In Section 5, we analyze the case in which the central bank keeps this information secret. Welfare is considered in Section 6; there we also explore the potential merits of communication as a substitute for monetary policy. We discuss several extensions to our model and issues related to the robustness of our results in Section 7. Section 8 concludes.

\section{RELATED LITERATURE}

We refrain from giving a detailed overview of the literature on transparency in monetary policy, which has been surveyed by Geraats (2002), Hahn (2002), and Blinder et al. (2008), ${ }^{4}$ and discuss only the papers most closely related to this analysis.

\subsection{Papers Related to the Analysis of Decision Transparency}

As explained before, two different kinds of transparency are examined in our paper: decision transparency and postdecision transparency. The beneficial 
effect of decision transparency may be reminiscent of Proposition 3 in Baeriswyl (2007), which demonstrates that transparency of the information underlying a central bank's decision is desirable for plausible parameter values. Baeriswyl (2007) assumes that the monetary-policy instrument cannot be observed directly and hence transparency improves the accuracy of firms' information. In contrast, in the present paper the instrument is observable and the public can infer the central bank's information from monetary policy even if the central bank does not publish the information. The beneficial effect of decision transparency is due to the elimination of inefficient equilibria. To the best of our knowledge, this point is new to the transparency literature. More broadly, our analysis of the scenario without decision transparency belongs to the class of signaling models in monetary policy [see Vickers (1986), Sibert (2002, 2003, 2009), and Gersbach and Hahn (2007, 2009)].

\subsection{Papers Related to the Analysis of Postdecision Transparency}

The analysis of postdecision transparency is more intricately linked to a number of papers in which agents are endowed with heterogeneous information [Morris and Shin (2002), Hellwig (2005), Baeriswyl (2007), Walsh (2007), Baeriswyl and Cornand (2010); in the following we will use MS, H, B, W, and BC for short]. This literature goes back to the seminal contribution by MS. MS capture the features of a Keynesian "beauty contest" by assuming that individuals benefit from making similar choices. Agents react more strongly to public signals over and against their private signals because they know that the former signals are observed by all and thus enable the coordination of actions. The stronger reaction of individuals to public information compared to private information is common to all papers reviewed here because all of them feature strategic complementarities.

To facilitate comparison between our analysis of postdecision transparency and the findings from the aforementioned works, it will be useful to introduce four dimensions along which the papers differ. First, whereas in all papers there are strategic complementarities and so aligning their choices is individually desirable to agents, the papers differ in the consequences of aligned actions for welfare. In MS and W, coordination of individual actions is not beneficial from a welfare perspective. ${ }^{5}$ This assumption leads to a skeptical assessment of transparency in MS. In the remaining papers, including the present one, price differences due to informational heterogeneity result in harmful microeconomic distortions. As a result, the stronger reaction to a public signal à la MS involves social benefits in the latter group of papers, which are not present in MS.

Second, the central bank's announcements may be observed by all agents $(\mathrm{H}$, $\mathrm{MS}, \mathrm{BC}$ ) or only some (B, W, and this paper). The assumption that the central bank's communication is unobserved by some price setters interacts in an important way with the assumption that coordinated price setting is socially beneficial. If both assumptions hold at the same time, a trade-off arises. Central-bank communication tends to align the choices of attentive price setters, but drives a wedge 
between the average prices chosen by attentive and inattentive price setters (BC and this paper).

Third, it has been well known since Angeletos and Pavan (2007) that the nature of business-cycle fluctuations determines the social value of information about these disturbances. It is therefore crucial to distinguish the papers along this dimension. $\mathrm{W}$ and $\mathrm{BC}$ consider demand shocks and markup shocks, the latter of which cannot be stabilized perfectly by the central bank. Roughly speaking, it may therefore be unfavorable to release information. A third type of disturbance is shocks to labor supply (BC). In contrast to markup shocks, labor supply shocks shift output and its socially optimal level in tandem.

Fourth, the papers differ in their assumptions on whether the central bank can choose a policy tool (B was the first to introduce this dimension into the literature reviewed here). In the analysis of postdecision transparency in the present paper, the central bank has adjusted its instrument in response to its private information available at that time. But as additional information becomes available afterward, the central bank can use communication as a substitute for monetary policy. Thus a distinctive feature of the present paper is that the policy instrument can be used only partially, namely in response to the first signal obtained by the central bank but not to the second. The explicit distinction between information available at the time of decision making and information that becomes available later is crucial for the effects of postdecision transparency, as we will see in Corollary 1, for example. The corollary shows that postdecision transparency has a benign impact on output variance if the information that was available to the central bank before it made its decision was sufficiently precise. Table 1 summarizes the differences between the papers along the four different dimensions.

With the help of the four dimensions, it is possible to trace the differences in welfare implications back to differences in assumptions. We focus on the relationship of this paper with MS and B. As can be seen from Table 1, MS differs from the analysis of postdecision transparency in the present paper along all dimensions discussed. Notably, coordination of individuals' actions is not socially desirable per se in MS, which leads to a less favorable assessment of the social value of transparency. However, it is important to stress that transparency is socially beneficial in their paper for a range of parameters. In fact, Svensson (2006) argues that this is the more plausible case. Similarly, the present paper involves a benign effect of postdecision transparency on output variance for plausible parameter values (see Proposition 4 and Corollary 1).

Despite the differences between B and the present paper, illustrated in Table 1, at least in one special case both papers can be compared easily. By setting the fraction of inattentive agents to zero (which effectively turns the "yes" in the second column for the present paper into a "no") and letting the central bank's first signal become completely uninformative (this turns the "partially" in the fourth column into a "yes"), our analysis can be related to B's analysis in his Section 3. There he examines the costs and benefits of communication when the central bank does not choose an action. Our analysis highlights the crucial role of the assumption about 
TABLE 1. Comparison of the analysis of postdecision transparency with related papers on transparency that consider heterogeneous signals of agents and individual benefits from coordination

\begin{tabular}{|c|c|c|c|c|}
\hline & $\begin{array}{l}\text { Aligned } \\
\text { choices } \\
\text { socially } \\
\text { desirable }\end{array}$ & $\begin{array}{c}\text { Some } \\
\text { agents } \\
\text { inattentive }\end{array}$ & Nature of shock(s) & $\begin{array}{l}\text { Policy } \\
\text { instrument } \\
\text { fixed }\end{array}$ \\
\hline $\begin{array}{l}\text { MS: Morris and Shin } \\
\quad(2002)\end{array}$ & No & No & $\begin{array}{l}\text { Shock to socially } \\
\text { optimal average } \\
\text { action of agents }\end{array}$ & Yes \\
\hline B: Baeriswyl (2007) & Yes & No & $\begin{array}{l}\text { Demand (uniformly } \\
\text { distributed on real } \\
\text { line) }\end{array}$ & Yes $^{a}$ \\
\hline $\begin{array}{c}\text { BC: Baeriswyl and } \\
\text { Cornand (2010) }\end{array}$ & Yes & Yes & $\begin{array}{l}\text { Labor supply and } \\
\text { markup }\end{array}$ & No \\
\hline W: Walsh (2007) & No & Yes & Demand and markup & No \\
\hline H: Hellwig (2005) & Yes & No & Demand & Yes \\
\hline $\begin{array}{l}\text { This paper: } \\
\text { postdecision } \\
\text { transparency }\end{array}$ & Yes & Yes & Demand & Partially \\
\hline
\end{tabular}

${ }^{a}$ This entry refers to his Section 3. B also considers the case in which the central bank chooses an instrument, but this scenario is not relevant for the comparison with postdecision transparency.

the distribution of demand shocks in B (see the respective column in Table 1). The fact that, in $\mathrm{B}$, demand shocks are distributed uniformly on the line of real numbers implies that, without a public signal, the private sector's estimate of the demand shock is correct on average. The release of a public signal distorts the average estimate toward this signal and leads to welfare losses. This particular distributional assumption in B makes the release of a public signal always harmful with regard to output stabilization, whereas postdecision transparency entails a reduction of output variance in the present paper for plausible parameter values. ${ }^{6}$

\section{MODEL}

\subsection{Basic Structure}

Our model can be derived from the small-scale general equilibrium model with flexible prices presented in Adam (2007). ${ }^{7}$ The economy is populated by a representative consumer, a central bank, and a continuum of firms, uniformly distributed on the interval $[0,1]$. To keep the analysis short, we omit the presentation of the underlying microeconomic model and directly depart from its log-linearized reduced form.

Firms choose the prices $p_{i}$ for their outputs. The following price-setting equation can be derived from the respective microeconomic optimization problem [see 
equation (3) in Adam (2007)]:

$$
p^{*}=p+\alpha y \text {. }
$$

The $(\log )$ optimal price $p^{*}$ depends on the (log) aggregate price level $p$, which reflects strategic complementarities. ${ }^{8}$ It also depends on (log) aggregate output $y$, which is common in macroeconomic models [see, e.g., Romer (2005), Ch. 6]. The optimal price may depend on aggregate output because aggregate output affects the costs of inputs, such as the real wage, or because of diminishing returns. The positive parameter $\alpha$ determines how strongly output variations influence the firm's optimal price.

To keep the model tractable, we adopt the assumption frequently used in the literature that output is affected through a quantity equation [see, e.g., Mankiw and Reis (2002)],

$$
y=m-p+\varepsilon,
$$

where $m$ denotes (log) money, which is the central bank's instrument. In addition, we have introduced a demand shock $\varepsilon$ that is normally distributed with expected value 0 and commonly known variance $\sigma_{\varepsilon}^{2} \cdot{ }^{9}$ We focus on an aggregate shock that affects all firms in the same way.

\subsection{Structure of Firms' Information}

We adopt the notion of sticky information introduced by Mankiw and Reis (2002). ${ }^{10}$ They argue that some firms may act on the basis of outdated information. The reason may be that information processing is costly and the benefits from always being well-informed may not be very large. More specifically, we assume that only a fraction $\lambda$ of firms update their information $(0<\lambda<1)$, whereas the remaining firms use outdated information: i.e., they only know the prior distributions of random variables. Without loss of generality, we arrange firms so that $[0, \lambda]$ corresponds to the set of firms updating their information (the attentive firms). The interval $] \lambda, 1]$ comprises the firms using outdated information (the inattentive firms). ${ }^{11}$

Even attentive price setters have only imperfect information about $\varepsilon$ when they choose their prices. Each of them receives a normally distributed signal $s_{i}$ with variance $\sigma_{i}^{2}$ and mean $\varepsilon$. The precision of firms' signals is identical; i.e., $\sigma_{i}^{2}$ is constant across attentive firms $i \in[0, \lambda]$. All variances are common knowledge, and all signals are independent from each other, conditional on $\varepsilon$. These assumptions imply, in particular, that the signals of price setters are different in general. In addition, the attentive price setters observe money growth $m$ and the information possibly released by the central bank. 


\subsection{Structure of the Central Bank's Information}

The shock $\varepsilon$ is also not known to the central bank with certainty when it conducts its monetary policy. We adopt the commonly accepted notion of substantial time lags between the implementation of monetary policy and its maximum effects, which were first documented by Friedman (1972). ${ }^{12}$ Consequently, some information obtained by the central bank may concern the near future, which cannot be influenced by conventional monetary policy measures. ${ }^{13}$ Communication may be used as a substitute for these measures.

More specifically, we assume that the central bank acquires private information about demand at two points in time. The central bank receives a first signal $s_{\mathrm{CB}, 0}$ before choosing its monetary policy instrument $m$. This signal is normally distributed with variance $\sigma_{\mathrm{CB}, 0}^{2}$ and mean $\varepsilon$. Another signal, $s_{\mathrm{CB}, 1}$, is discovered by the central bank after it has made its decision. This signal is drawn from a normal distribution with variance $\sigma_{\mathrm{CB}, 1}^{2}$ and mean $\varepsilon$.

\subsection{Loss Functions}

As has been demonstrated by Woodford (2002) and Adam (2007) (see equation (66) in the latter paper), the social loss function, which can be derived from the utility of the representative consumer, corresponds to a weighted average of the variance of prices and the variance of output. We apply this result and derive an expression for the variance of prices in the context of our model in Appendix A, which entails the following expression for social losses:

$$
L_{\mathrm{SOC}}=\pi^{2}+a_{\mathrm{SOC}} y^{2}+b_{\mathrm{SOC}} \operatorname{Var}_{i \in[0, \lambda]} p_{i}
$$

where $a_{\text {SOC }}$ and $b_{\text {SOC }}$ are positive parameters, $\pi:=p-p_{-1}$ denotes the inflation rate, and $p_{-1}$ is the log price level that prevailed in the previous period -1 , which is not modeled explicitly. ${ }^{14}$ Henceforth we assume without loss of generality that $p_{-1}=0 . \operatorname{Var}_{i \in[0, \lambda]} p_{i}$ is the variance of the prices of agents on the interval $[0, \lambda]$, which comprises those agents who update their information.

Equation (3) encompasses the standard loss function that depends only on deviations of inflation from its target and on deviations of output from the natural level. The term $a_{\mathrm{SOC}} y^{2}$ reflects the costs stemming from deviations of output from its socially optimal level. The terms $\pi^{2}$ and $b_{\mathrm{SOC}} \operatorname{Var}_{i \in[0, \lambda]} p_{i}$ capture the distortions arising from price dispersion. First, the average price chosen by firms in $[0, \lambda]$ differs from the prices selected by firms in $] \lambda, 1]$. This leads to losses proportional to $\pi^{2}$. Second, the firms in $[0, \lambda]$ choose different prices because of heterogeneous information. This results in the term proportional to $\operatorname{Var}_{i \in[0, \lambda]} p_{i}$ in the social loss function. In Appendix A, we demonstrate that

$$
b_{\mathrm{SOC}}=\frac{\lambda^{2}}{1-\lambda} .
$$


In principle, $a_{\mathrm{SOC}}$ can also be pinned down by the parameters of the underlying small-scale general equilibrium model [see Adam (2007)].

The central bank chooses $m$ to minimize its loss function,

$$
L_{\mathrm{CB}}=\pi^{2}+a_{\mathrm{CB}} y^{2}+b_{\mathrm{CB}} \underset{i \in[0, \lambda]}{\operatorname{Var}_{i}} p_{i}
$$

where $a_{\mathrm{CB}}$ and $b_{\mathrm{CB}}$ are weakly positive parameters. Parameter $a_{\mathrm{CB}}$ describes the degree of the central bank's conservatism. We have included the term $b_{\mathrm{CB}} \operatorname{Var}_{i \in[0, \lambda]} p_{i}$ in (5) to make the central bank's loss function formally equivalent to the social loss function. ${ }^{15}$ However, we can neglect this term when computing the central bank's optimal choice of monetary policy. To see this, recall that $\operatorname{Var}_{i \in[0, \lambda]} p_{i}$ describes the distortions stemming from heterogeneous prices of attentive firms. Because all of these firms observe the same value of $m$ and respond to changes in $m$ in an identical manner, ${ }^{16}$ the central bank cannot affect $\operatorname{Var}_{i \in[0, \lambda]} p_{i}$ by its choice of $m$.

\subsection{Timing}

The sequence of events is as follows:

1. Nature draws the demand shock $\varepsilon$.

2. The central bank learns the value of $s_{\mathrm{CB}, 0}$.

3. Depending on the transparency regime (decision transparency or decision opacity), the central bank may or may not make $s_{\mathrm{CB}, 0}$ public.

4. The central bank selects $m$, which is publicly observable.

5. The central bank learns the value of $s_{\mathrm{CB}, 1}$.

6. Depending on the transparency regime (postdecision transparency or postdecision opacity), the central bank may or may not make $s_{\mathrm{CB}, 1}$ public.

7. Each firm in $[0, \lambda]$ privately observes the value of its signal $s_{i}$. Additionally, it obtains the information published by the central bank and $m$. Firms in $] \lambda, 1]$ are inattentive and do not receive private signals, the information released by the central bank and the central bank's choice of $m$.

8. All firms choose their prices.

We stress that under decision transparency or postdecision transparency, the central bank is committed to truthfully reveal $s_{\mathrm{CB}, 0}$ or $s_{\mathrm{CB}, 1}$, respectively. In addition, it is committed to withholding these signals under decision opacity and postdecision opacity. Hence, in line with the bulk of the literature on transparency in monetary policy, we assume that the central bank cannot lie. Moreover, it cannot make its decision to publish its signals dependent on their realizations. Allowing for these possibilities would open up an interesting avenue for future research.

\section{TRANSPARENCY OF INFORMATION UNDERLYING MONETARY POLICY}

In this section we assume that the central bank publishes the information underlying its monetary-policy decision, i.e., $s_{\mathrm{CB}, 0}$. Moreover, we assume for the moment 
that the central bank also makes $s_{\mathrm{CB}, 1}$ public. As a first step, we specify each firm's estimate of $\varepsilon$ [see DeGroot (1970)],

$$
\mathbf{E}_{i}[\varepsilon]=\gamma_{\mathrm{CB}, 0} s_{\mathrm{CB}, 0}+\gamma_{\mathrm{CB}, 1} s_{\mathrm{CB}, 1}+\gamma_{i} s_{i},
$$

where we have introduced

$$
\begin{aligned}
\gamma_{\mathrm{CB}, 0} & :=\frac{\frac{1}{\sigma_{\mathrm{CB}, 0}^{2}}}{\frac{1}{\sigma_{\mathrm{CB}, 0}^{2}}+\frac{1}{\sigma_{\mathrm{CB}, 1}^{2}}+\frac{1}{\sigma_{i}^{2}}+\frac{1}{\sigma_{\varepsilon}^{2}}}, \\
\gamma_{\mathrm{CB}, 1} & :=\frac{\frac{1}{\sigma_{\mathrm{CB}, 1}^{2}}}{\frac{1}{\sigma_{\mathrm{CB}, 0}^{2}}+\frac{1}{\sigma_{\mathrm{CB}, 1}^{2}}+\frac{1}{\sigma_{i}^{2}}+\frac{1}{\sigma_{\varepsilon}^{2}}}, \\
\gamma_{i} & :=\frac{\frac{1}{\sigma_{i}^{2}}}{\frac{1}{\sigma_{\mathrm{CB}, 0}^{2}}+\frac{1}{\sigma_{\mathrm{CB}, 1}^{2}}+\frac{1}{\sigma_{i}^{2}}+\frac{1}{\sigma_{\varepsilon}^{2}}} .
\end{aligned}
$$

If a firm has no information about the shock and $m$, it will always expect $\mathbf{E}[y]=0$ and $\mathbf{E}[p]=p_{-1}=0$. This results from the observations that the central bank pursues an inflation target of zero and that demand shocks are zero on average. Inserting $\mathbf{E}[y]=0$ and $\mathbf{E}[p]=p_{-1}=0$ into (1), we can conclude that it is optimal for all firms that do not update their information to choose a price of $p_{-1}=0$.

Next we derive the choices that are optimal for the firms in $[0, \lambda]$. Using (1), (2), and (6), the price of a firm $i \in[0, \lambda]$ can be stated as

$$
\begin{aligned}
p_{i} & =\mathbf{E}_{i}[p]+\alpha\left(m-\mathbf{E}_{i}[p]+\mathbf{E}_{i}[\varepsilon]\right) \\
& =\alpha m+(1-\alpha)\left(\lambda \mathbf{E}_{i}\left[p_{j}\right]+(1-\lambda) p_{-1}\right)+\alpha\left(\gamma_{\mathrm{CB}, 0} s_{\mathrm{CB}, 0}+\gamma_{\mathrm{CB}, 1} s_{\mathrm{CB}, 1}+\gamma_{i} s_{i}\right),
\end{aligned}
$$

where $\mathbf{E}_{i}\left[p_{j}\right]$ is firm $i$ 's expectation about the price chosen by an arbitrary other firm $j$ in $[0, \lambda]$. As we wish to focus on the case where there are complementarities in price setting, we assume that $\alpha<1$ for the remainder of the paper [see also Branch et al. (2009)]. According to (10), this assumption guarantees that firm $i$ 's price choice is a positive function of the other firms' prices.

We conjecture that $p_{i}$ can be written as

$$
p_{i}=\psi_{m} m+\psi_{\mathrm{CB}, 0} s_{\mathrm{CB}, 0}+\psi_{\mathrm{CB}, 1} s_{\mathrm{CB}, 1}+\psi_{i} s_{i}
$$

where $\psi_{m}, \psi_{\mathrm{CB}, 0}, \psi_{\mathrm{CB}, 1}$, and $\psi_{i}$ are coefficients left to be determined. Inserting (11) 
into (10), applying $\mathbf{E}_{i}\left[s_{j}\right]=E_{i}[\varepsilon]$ and (6), and equating coefficients gives

$$
\begin{aligned}
\psi_{m} & =\frac{\alpha}{1-\lambda(1-\alpha)}, \\
\psi_{\mathrm{CB}, 0} & =\frac{\alpha \gamma_{\mathrm{CB}, 0}}{(1-\lambda(1-\alpha))\left(1-\gamma_{i} \lambda(1-\alpha)\right)}, \\
\psi_{\mathrm{CB}, 1} & =\frac{\alpha \gamma_{\mathrm{CB}, 1}}{(1-\lambda(1-\alpha))\left(1-\gamma_{i} \lambda(1-\alpha)\right)}, \\
\psi_{i} & =\frac{\alpha \gamma_{i}}{1-\gamma_{i} \lambda(1-\alpha)} .
\end{aligned}
$$

We assume that an appropriate law of large numbers holds and thus the average signal $s_{i}$ is identical to $\varepsilon .{ }^{17}$ Consequently, with the help of (11), the aggregate price level can be written as $\lambda$ times the average price chosen by the firms in $[0, \lambda]$ plus $1-\lambda$ times $p_{-1}=0$, which is the price selected by the firms in ] $\left.\lambda, 1\right]$ :

$$
p=\lambda\left(\psi_{m} m+\psi_{\mathrm{CB}, 0} s_{\mathrm{CB}, 0}+\psi_{\mathrm{CB}, 1} s_{\mathrm{CB}, 1}+\psi_{i} \varepsilon\right) .
$$

As a next step, we compute the central bank's optimal choice of $m$. Minimizing (5) subject to (16) and applying $\pi=p-p_{-1}=p$ yields the following first-order condition:

$$
\mathbf{E}_{\mathrm{CB}, 0}\left[\lambda \psi_{m} p+a_{\mathrm{CB}}\left(1-\lambda \psi_{m}\right)(m-p+\varepsilon)\right]=0 .
$$

$\mathbf{E}_{\mathrm{CB}, 0}$ denotes the central bank's expectations after observing $s_{\mathrm{CB}, 0}$ but not $s_{\mathrm{CB}, 1}$. Utilizing (17) and $\mathbf{E}_{\mathrm{CB}, 0}\left[s_{\mathrm{CB}, 1}\right]=\mathbf{E}_{\mathrm{CB}, 0}[\varepsilon]=\hat{\gamma}_{\mathrm{CB}, 0} s_{\mathrm{CB}, 0}$ where

$$
\hat{\gamma}_{\mathrm{CB}, 0}:=\frac{1 / \sigma_{\mathrm{CB}, 0}^{2}}{1 / \sigma_{\mathrm{CB}, 0}^{2}+1 / \sigma_{\varepsilon}^{2}},
$$

we obtain

$$
m=-\hat{\gamma}_{\mathrm{CB}, 0} s_{\mathrm{CB}, 0} .
$$

This result is highly plausible. The central bank chooses $m$ so as to eliminate the expected impact of the demand shock on output, which amounts to $\mathbf{E}_{\mathrm{CB}, 0}[\varepsilon]=\hat{\gamma}_{\mathrm{CB}, 0} s_{\mathrm{CB}, 0}$. Using $\mathbf{E}_{\mathrm{CB}, 0}[\varepsilon]=\mathbf{E}_{\mathrm{CB}, 0}\left[s_{\mathrm{CB}, 1}\right]=\hat{\gamma}_{\mathrm{CB}, 0} s_{\mathrm{CB}, 0}$ and $\hat{\gamma}_{\mathrm{CB}, 0} \psi_{m}=\psi_{\mathrm{CB}, 0}+\left(\psi_{\mathrm{CB}, 1}+\psi_{i}\right) \hat{\gamma}_{\mathrm{CB}, 0}$, which can be readily verified, (2) and (16) can be simplified to $\mathbf{E}_{\mathrm{CB}, 0}[\pi]=0$ and $\mathbf{E}_{\mathrm{CB}, 0}[y]=0$. Because demand shocks involve no tradeoff between stabilizing output and inflation, the central bank can choose its instrument in a way such that both output and inflation are identical to their targets in expected terms. Equations (11)-(16) and (19) give a complete characterization of the equilibrium if the central bank publishes the information underlying its monetary-policy decision.

So far, we have derived the solution if the central bank operates under both decision transparency and postdecision transparency. It is crucial to note that it is straightforward to construct the solution under decision transparency and 
postdecision opacity. We simply have to set $\sigma_{\mathrm{CB}, 1}^{2} \rightarrow \infty$. In this case, the signal $s_{\mathrm{CB}, 1}$ published by the central bank becomes completely uninformative, which corresponds to postdecision opacity.

\section{OPACITY OF INFORMATION UNDERLYING MONETARY POLICY}

While we have assumed so far that the central bank publishes the information that it has used to reach its decision, we consider in the following the case where the central bank keeps this information secret. Nevertheless the firms may be able to infer this information from the policy of the central bank. Consequently, the analysis of the present scenario corresponds to a signaling game. As in the previous section, we initially adopt the assumption that $s_{\mathrm{CB}, 1}$ is public. By taking $\sigma_{\mathrm{CB}, 1}^{2}$ to infinity, the case where the central bank is completely silent with respect to both $s_{\mathrm{CB}, 0}$ and $s_{\mathrm{CB}, 1}$ is readily constructed.

We conjecture that the firms believe that the central bank's policy is a linear function of its signal $s_{\mathrm{CB}, 0}$,

$$
m=\phi^{O} s_{\mathrm{CB}, 0},
$$

with some arbitrary coefficient $\phi^{O} \neq 0 .{ }^{18}$ Then firms can derive $s_{\mathrm{CB}, 0}$ by using (20), and the optimal price set by a firm $i$ is given by (11)-(15), with $m / \phi^{O}$ substituted for $s_{\mathrm{CB}, 0}$ :

$$
p_{i}=\psi_{m} m+\psi_{\mathrm{CB}, 0} \frac{m}{\phi^{O}}+\psi_{\mathrm{CB}, 1} s_{\mathrm{CB}, 1}+\psi_{i} s_{i} .
$$

Analogously to (16), the price level under decision opacity is

$$
p=\lambda\left(\psi_{m} m+\psi_{\mathrm{CB}, 0} \frac{m}{\phi^{O}}+\psi_{\mathrm{CB}, 1} s_{\mathrm{CB}, 1}+\psi_{i} \varepsilon\right) .
$$

According to (22), the impact of a marginal change in $m$ on the price level is different from the effect in the scenario considered in the previous section because a change in $m$ also influences the firms' estimate of the central bank's signal $s_{\mathrm{CB}, 0}$.

In Appendix B, we show that, provided that the public believes that the central bank follows a policy $m=\phi^{O} s_{\mathrm{CB}, 0}$, it is optimal for the central bank to pursue a policy $m=\Phi^{O}\left(\phi^{O}\right) s_{\mathrm{CB}, 0}$, where

$$
\begin{gathered}
\Phi^{O}\left(\phi^{O}\right)=-\left\{\lambda^{2}\left(\psi_{i}+\psi_{\mathrm{CB}, 1}\right)\left(\psi_{m}+\frac{\psi_{\mathrm{CB}, 0}}{\phi^{O}}\right)\right. \\
\left.-a_{\mathrm{CB}}\left[1-\lambda\left(\psi_{i}+\psi_{\mathrm{CB}, 1}\right)\right]\left[1-\lambda\left(\psi_{m}+\frac{\psi_{\mathrm{CB}, 0}}{\phi^{O}}\right)\right]\right\} \\
\times \frac{\hat{\gamma}_{\mathrm{CB}, 0}}{\lambda^{2}\left(\psi_{m}+\frac{\psi_{\mathrm{CB}, 0}}{\phi^{O}}\right)^{2}+a_{\mathrm{CB}}\left[1-\lambda\left(\psi_{m}+\frac{\psi_{\mathrm{CB}, 0}}{\phi^{o}}\right)\right]^{2}} .
\end{gathered}
$$


It is important to note that the central bank's optimal responsiveness to its signal $s_{\mathrm{CB}, 0}$, i.e., $\Phi^{O}\left(\phi^{O}\right)$, is a function of $\phi^{O}$, which is the strength with which the public expects the central bank to react to its signal $s_{\mathrm{CB}, 0}$. This is a consequence of the fact that the public attempts to infer the central bank's signal from its instrument. As the attentive firms' price choices depend on their expectations of the central bank's signal, $\phi^{O}$ influences the firms' response to the central bank's choice of $m$ [see (21)] and thus, in turn, the monetary policy that is optimal for the central bank.

In equilibrium, the firms' beliefs have to be correct and so $\phi^{O}=\Phi^{O}\left(\phi^{O}\right)$ must hold; i.e., we need to identify fixed points of $\Phi^{O}\left(\phi^{O}\right)$. In Appendix C, we show that $\Phi^{O}\left(\phi^{O}\right)$ has two fixed points that satisfy $\phi^{O} \neq 0:{ }^{19}$

$$
\begin{aligned}
\phi_{\text {fund }}^{O} & =-\hat{\gamma}_{\mathrm{CB}, 0} \\
\phi_{\text {add }}^{O} & =-\frac{\lambda \psi_{m}-a_{\mathrm{CB}}\left(1-\lambda \psi_{m}\right)}{\lambda^{2}\left(\psi_{m}\right)^{2}+a_{\mathrm{CB}}\left(1-\lambda \psi_{m}\right)^{2}} \lambda \psi_{\mathrm{CB}, 0} .
\end{aligned}
$$

Each of these fixed points corresponds to an equilibrium. We label the first solution, $\phi_{\text {fund }}^{O}$, fundamental because it is identical to the solution when the central bank is transparent about its signal $s_{\mathrm{CB}, 0}$ [compare (19)]. The additional solution $\phi_{\text {add }}^{O}$, however, arises only if the central bank withholds its information about $s_{\mathrm{CB}, 0}$.

We summarize our findings in the following proposition:

PROPOSITION 1. If the central bank does not publish its private information about $s_{\mathrm{CB}, 0}$, two equilibria exist. In both equilibria, the firms choose their prices in line with (21). In the fundamental equilibrium, the central bank pursues the same policy as in the case where it publishes $s_{\mathrm{CB}, 0}$, i.e., $m=-\hat{\gamma}_{\mathrm{CB}, 0} s_{\mathrm{CB}, 0}$. In the additional equilibrium, the central bank chooses $m=\phi_{\mathrm{add}}^{O} s_{\mathrm{CB}, 0}$, where $\phi_{\mathrm{add}}^{O}$ is given by (25).

To illustrate Proposition 1, we introduce the following example. Suppose $\sigma_{\mathrm{CB}, 0}^{2} \rightarrow 0$, which implies that $s_{\mathrm{CB}, 0}$ reveals the demand shock perfectly $\left(\varepsilon=s_{\mathrm{CB}, 0}\right)$. In this case, we obtain $\gamma_{\mathrm{CB}, 0}=\hat{\gamma}_{\mathrm{CB}, 0}=1, \gamma_{i}=0, \gamma_{\mathrm{CB}, 1}=0$, $\psi_{m}=\psi_{\mathrm{CB}, 0}=\alpha /[1-\lambda(1-\alpha)], \psi_{\mathrm{CB}, 1}=0$, and $\psi_{i}=0$ [see (7)-(9), (12)-(15), and (18)]. For concreteness, we consider the numerical values $a_{\mathrm{CB}}=1, \lambda=1 / 2$, and $\alpha=1 / 2$, which entail $\psi_{m}=\psi_{\mathrm{CB}, 0}=\alpha /(1-\lambda(1-\alpha))=2 / 3$. With the help of (22), the price level as a function of $m$ can be written as

$$
p=\frac{1}{3}\left(1+1 / \phi^{O}\right) m .
$$

Interestingly, $\frac{1}{3}\left(1+1 / \phi^{O}\right)$ is a strictly monotonically decreasing function of $\phi^{O}$ for $\phi^{O}>0$. Consequently, the more strongly the firms expect the central bank to respond to shocks (or, equivalently, the higher $\phi^{O}$ ), the more difficult it is for the central bank to affect the price level and thus the more vigorous its policy has to be to influence the price level in a particular way. This positive relationship suggests that multiple equilibria might exist. 


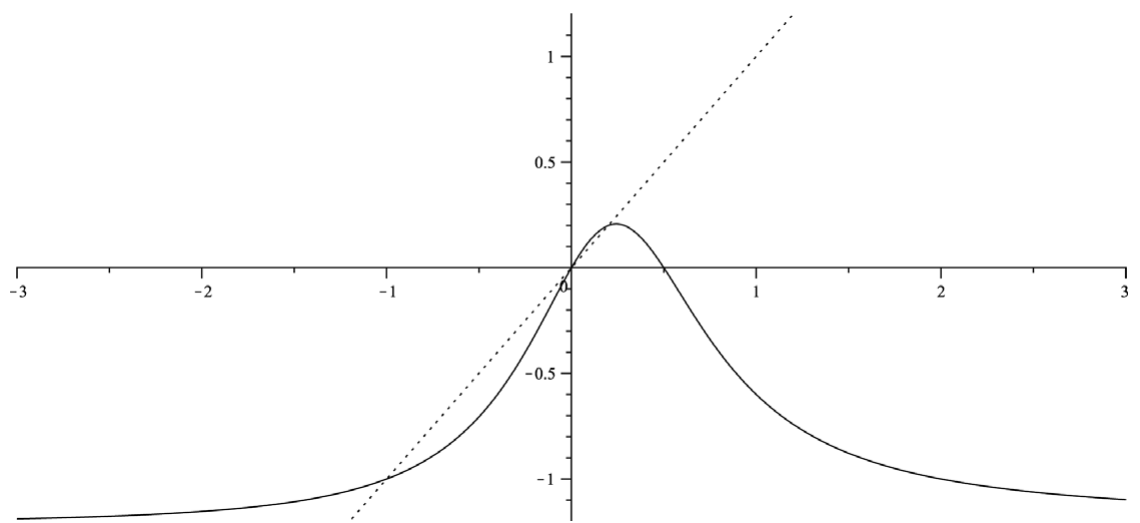

FigURE 1. $\Phi^{O}\left(\phi^{O}\right)$ for the example described in the text (solid graph) and the identity function $f\left(\phi^{O}\right)=\phi^{O}$ (dotted line).

To explore this issue further, we plot $\Phi^{O}\left(\phi^{O}\right)$ [see (23)] and the identity function in Figure 1. In an equilibrium the two graphs must intersect. This happens three times, at $\phi^{O}=-1, \phi^{O}=0$, and $\phi^{O}=1 / 5$. The value $\phi^{O}=0$ does not correspond to a separating equilibrium because the same value of $m$ is chosen irrespective of $s_{\mathrm{CB}, 0}$ (see also note 18 ).

Next we explain the shape of $\Phi^{O}\left(\phi^{O}\right)$ and, in particular, focus on the points where $\Phi^{O}\left(\phi^{O}\right)$ and the identity function intersect. It is instructive to consider values of $\phi^{O}$ that are very close to zero. Then $p=\frac{1}{3} \cdot\left(1+1 / \phi^{O}\right) m$ responds very strongly to even small choices of $m$. As a result, the central bank will choose very small values of $m$ in order to prevent the first term in its loss function, $\pi^{2}=p^{2}$, from being very large. This leads us to the conclusion that $\Phi^{O}\left(\phi^{O}\right)$ must be close to zero for values of $\phi^{O}$ around zero. This observation can be verified from Figure 1.

Now suppose that the firms believe that $\phi^{O}=-1$. In this case, the price level is constant and cannot be influenced by the central bank [according to (26), $p=0$ ]. While attentive firms would like to raise their prices for a hypothetical increase in $m$ because this increase would tend to increase nominal demand $m+\varepsilon$, this effect is exactly offset by a one-to-one decrease in the firms' expectations about $\varepsilon$ (these expectations are $m / \phi^{O}=-m$ ). As for $\phi^{O}=-1$, the central bank cannot influence the term $\pi^{2}=p^{2}=0$ in its loss function; it aims at minimizing $y^{2}=(m-p+\varepsilon)^{2}=\left(m+s_{\mathrm{CB}, 0}\right)^{2}$, in effect. Obviously it is optimal to set $m=-s_{\mathrm{CB}, 0}$, which means that $\Phi^{O}(-1)=-1$. The fixed point at $\phi^{O}=-1$ corresponds to the fundamental equilibrium, where the central bank chooses $m$ equal to the negative of its expectation of the demand shock.

Importantly, there is another point where the identity function and $\Phi^{O}\left(\phi^{O}\right)$ intersect $\left[\Phi^{O}(1 / 5)=1 / 5\right]$. For $\phi^{O}=1 / 5$, (26) simplifies to $p=2 m$, which implies a comparably strong effect of changes in $m$ on prices. This can be explained as follows. First, an increase in $m$ raises nominal demand $m+\varepsilon$ directly, which 
in itself induces firms to raise prices. Second, for $\phi^{O}=1 / 5$, even small changes in $m$ lead to comparably large changes in the firms' expectations about the shock (their expectation for the shock being $m / \phi^{O}=5 m$ ).

What is the optimal response to a shock of $\varepsilon=+1$ if $\phi^{O}=1 / 5$ ? A value of $m=$ 1 would stabilize output perfectly, as $y=m-p+\varepsilon=m-2 m+\varepsilon=-m+\varepsilon=0$. However, such a value of $m$ would entail a large value of $p^{2}=4 m^{2}=4$. As the central bank optimally trades off losses from $p^{2}$ and $y^{2}$, it chooses a moderate response of $m=1 / 5$. To sum up, if the attentive firms expect the central bank to pursue the policy $m=\phi_{\text {add }}^{O} \varepsilon=1 / 5 \cdot \varepsilon$, this policy will indeed be optimal. In contrast, the policy that is optimal in the fundamental equilibrium would be inadequate in this case. If the central bank chose $m=\phi_{\text {fund }}^{O} \varepsilon=-\varepsilon$, both $p^{2}=4 m^{2}=4$ and $y^{2}=(m-p+\varepsilon)^{2}=(m-2 m+\varepsilon)^{2}=4$ would be very high.

Although we have focused on the case with decision opacity and postdecision transparency in this section, the results for a combination of decision opacity and postdecision opacity can easily be obtained by taking $\sigma_{\mathrm{CB}, 1}^{2}$ to infinity. Having derived the equilibria for all transparency regimes considered in this paper, we now turn to an analysis of welfare.

\section{WELFARE}

With respect to the fundamental equilibrium, the welfare consequences of the publication of $s_{\mathrm{CB}, 0}$ are clear because the fundamental equilibrium is identical to the solution under decision transparency. However, it is unclear as yet whether the additional equilibrium leads to lower or higher social losses than the scenario with decision transparency. This question is addressed in this section. In addition, we examine the impact of postdecision transparency on welfare.

\subsection{Additional Equilibrium vs. Fundamental Equilibrium}

In our example in the previous section, the central bank can stabilize output and inflation perfectly in the fundamental equilibrium ( $y=0$ and $\pi=0)$. In contrast, this is not possible in the additional equilibrium. Together with $\operatorname{Var}_{i \in[0, \lambda]} p_{i}=0$, which holds in both equilibria, this leads us to the conclusion that the fundamental equilibrium is socially desirable in the example discussed in Section 5. ${ }^{20}$

This finding about welfare can be investigated in more detail in Figure 2, where we display the efficient frontier in the additional equilibrium as a solid line. The efficient frontier gives the minimum value of the variance of inflation that can be attained for a specific output variance. The efficient frontier is downward-sloping, reflecting a trade-off between output and inflation stabilization. The central bank will select the point on this curve that corresponds to the indifference curve with the lowest losses, which is displayed as a dotted line. ${ }^{21}$

The efficient frontier in the fundamental equilibrium $\left(\phi^{O}=\phi_{\text {fund }}^{O}=-1\right)$ is substantially more favorable in the example under consideration, where the central bank observes the shock perfectly before deciding on its monetary policy. ${ }^{22}$ In this 


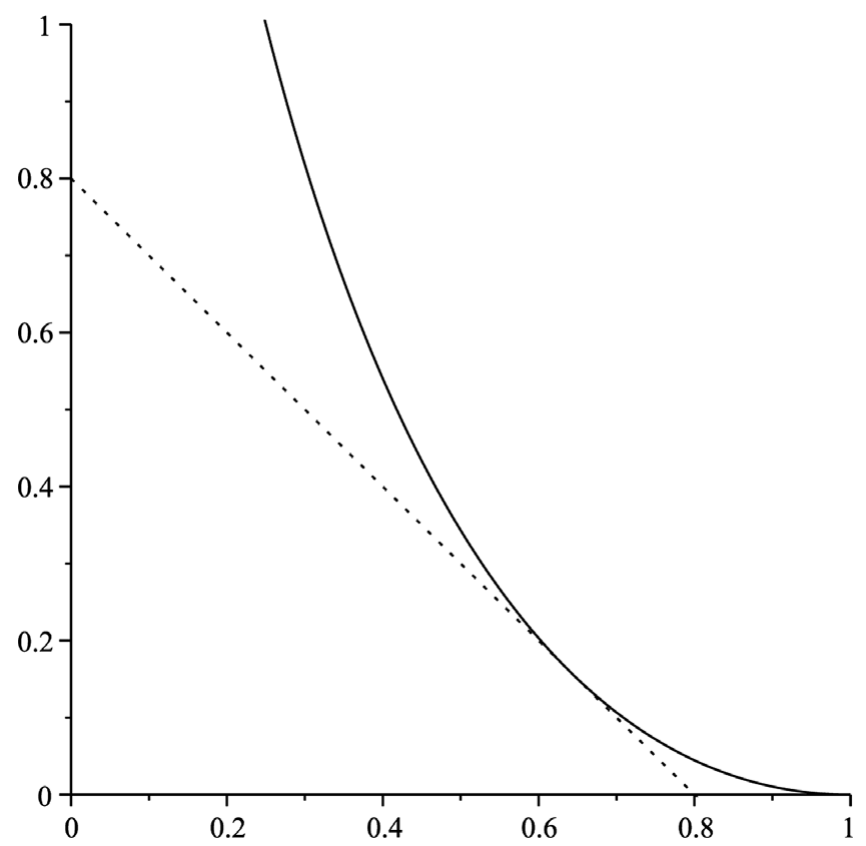

FIGURE 2. Efficient frontier for $\phi^{O}=\phi_{\text {fund }}^{O}$ (solid line) and the corresponding indifference curve of the central bank (dotted line). The variance of inflation is displayed on the vertical axis, the variance of output on the horizontal axis. The variance of $\varepsilon$ is normalized to one.

extreme case, the efficient frontier collapses to the origin and the central bank can ensure zero variance of both inflation and output. This point cannot be achieved for $\phi^{O}=\phi_{\text {add }}^{O}{ }^{23}$

The following proposition, which is proved in Appendix D, demonstrates that our finding about the harmful consequences of additional equilibria holds in general.

PROPOSITION 2. For a given regime of postdecision transparency, the additional equilibrium always leads to higher expected values of $\pi^{2}+b_{\mathrm{SOC}} \operatorname{Var}_{i \in[0, \lambda]} p_{i}$ and $y^{2}$ than the fundamental equilibrium. Consequently, the additional equilibrium unequivocally involves lower welfare.

Thus we arrive at the important conclusion that, irrespective of the postdecision transparency regime, the central bank should always publicize the information that led to its decision. ${ }^{24}$ Put differently, when looking for the socially optimal communication framework, we can safely disregard any framework that does not feature decision transparency.

\subsection{Publishing Information the Central Bank Obtains after Its Decision}

In the following, we assume that the central bank behaves socially optimally with respect to decision transparency and publishes $s_{\mathrm{CB}, 0}$. The next step is to evaluate 
whether the publication of the signal $s_{\mathrm{CB}, 1}$, which the central bank receives after it has chosen monetary policy, is desirable. This can be achieved by comparing the solutions obtained under decision transparency for $\sigma_{\mathrm{CB}, 1}^{2} \rightarrow \infty$ with the solution for a finite value of $\sigma_{\mathrm{CB}, 1}^{2}$.

We begin our analysis by examining the first and second of the three components of the social loss function (3), namely $\pi^{2}$ and $\operatorname{Var}_{i \in[0, \lambda]} p_{i}$. In Appendix E, we show

PROPOSITION 3. Postdecision transparency lowers the ex ante expected value of $\operatorname{Var}_{i \in[0, \lambda]} p_{i}$ but increases the ex ante expected value of $\pi^{2}$.

Hence postdecision transparency has two opposing effects on the distortions caused by price differences across firms. First, if the central bank publishes $s_{\mathrm{CB}, 1}$, this additional source of information will induce attentive firms to pay less attention to their own heterogeneous signals when they choose their prices. This leads to a reduction in $\operatorname{Var}_{i \in[0, \lambda]} p_{i}$, which is in line with Hellwig (2005). Second, the additional source of information $s_{\mathrm{CB}, 1}$ aggravates the gap between the prices chosen by attentive firms and those selected by inattentive firms. The expected value of $\pi^{2}$, which corresponds to the losses caused by this gap, is therefore higher under postdecision transparency.

Finally, we turn to the impact postdecision transparency has on the deviations of output from potential output. In Appendix F we show

PROPOSITION 4. If

$$
\frac{\frac{1}{\sigma_{i}^{2}}}{\frac{1}{\sigma_{\mathrm{CB}, 0}^{2}}+\frac{1}{\sigma_{i}^{2}}+\frac{1}{\sigma_{\varepsilon}^{2}}}<\frac{1}{\lambda} \cdot \frac{2(1-\lambda)+\lambda \alpha}{2(1-\lambda)+\lambda \alpha(1+\alpha)},
$$

postdecision transparency lowers the ex ante expected value of $y^{2}$.

Under which circumstances does the condition stated in the proposition hold? First, we note that $\frac{1}{\lambda} \cdot \frac{2(1-\lambda)+\lambda \alpha}{2(1-\lambda)+\lambda \alpha(1+\alpha)}>\frac{1}{2}$ for all admissible values of $\alpha$ and $\lambda$. Second, $\left(\frac{1}{\sigma_{i}^{2}}\right) /\left(\frac{1}{\sigma_{\mathrm{CB}, 0}^{2}}+\frac{1}{\sigma_{i}^{2}}+\frac{1}{\sigma_{\varepsilon}^{2}}\right)<\frac{1}{2}$ if $\sigma_{\mathrm{CB}, 0}^{2}<\sigma_{i}^{2}$. A sufficient condition for postdecision transparency to have a beneficial effect on the variance of output is therefore that the central bank's first signal $s_{\mathrm{CB}, 0}$ is superior to $s_{i}$, which is the private information of an individual firm. ${ }^{25}$

COROLLARY 1. If the central bank's information available at the time when monetary policy is chosen is superior to private information $\left(\sigma_{\mathrm{CB}, 0}^{2}<\sigma_{i}^{2}\right)$, postdecision transparency will lead to a reduction in output variance. ${ }^{26}$

\section{EXTENSIONS AND ROBUSTNESS}

In this section we discuss possible extensions to our framework and the robustness of our results. We focus on the following issues: the potential conflict between 
the central bank and society with respect to transparency, the substitution between communication and monetary policy, and the roles of the two kinds of information asymmetries considered in this paper.

\subsection{Potential Conflict of Interests}

Suppose the central bank could determine its transparency regime freely. Accordingly, it could make the choices between decision transparency and decision opacity and between postdecision transparency and postdecision opacity. Would it deliver the optimal transparency regime in our model? Although it would be optimal for the central bank to provide an analysis of the information underlying its decisions if its interests were accurately described by the loss function (5) (and thus there were no additional motives for opacity), a discrepancy may arise between the socially optimal level of postdecision transparency and the one preferred by the central bank. For example, let us assume that the central bank's weight on the output target is identical to the respective weight in the social loss function, i.e., $a_{\mathrm{CB}}=a_{\mathrm{SOC}}$. Moreover, as no central bank is endowed with the objective of eliminating relative price distortions in addition to the objective of stabilizing inflation, we can plausibly assume $b_{\mathrm{CB}}=0$. In this case, the central bank disregards one of the benefits of postdecision transparency, namely the reduction of distortionary price variation. If the central bank neglects this effect, it may choose decision opacity, although transparency would be optimal. This potential conflict of interest is further exacerbated by the fact that most central bankers are more conservative than society, i.e., put a higher emphasis on inflation stabilization compared to output stabilization. Because postdecision transparency ameliorates deviations of output from its target, while raising inflation variance, conservative central bankers' choice of transparency may be biased toward opacity.

Hence, our model may shed some light on the observation that many central banks became more transparent only as a result of substantial outside pressure. For example, the Federal Reserve fended off early attempts to force it to release more information [see Goodfriend (1986)]. Similarly, the European Central Bank in its start-up period was under heavy criticism for being opaque [see Buiter (1999), among others]. Since then it has become gradually more transparent.

\subsection{Substitution between Communication and Monetary Policy}

In Proposition 4, we have shown that communication can be used to stabilize the output gap. In this sense, communication may be useful as a substitute for monetary policy when the central bank's hands are tied by implementation lags. This raises the question of whether it could be optimal for the central bank to reveal $s_{\mathrm{CB}, 0}$ but to remain inactive, thereby relying exclusively on communication to stabilize the economy. Such behavior can never be optimal, as the policy described by (19) has been shown to be optimal and thus would be strictly superior. Consequently, communication does not obviate the need for monetary-policy action. 


\subsection{Role of Different Sources of Information Asymmetries}

Finally, we discuss the role of the two sources of information asymmetries across firms, heterogeneous signals and inattentiveness, for our findings on decision transparency. Evaluating $\phi_{\text {add }}^{O}$ [see (25)] for $\lambda \rightarrow 1$ (all firms are attentive) and $\sigma_{i}^{2} \rightarrow \infty$ (individual signals are uninformative) reveals that $\phi_{\text {add }}^{O}=-\left(1 / \sigma_{\mathrm{CB}, 0}^{2}\right) /\left(1 / \sigma_{\mathrm{CB}, 0}^{2}+1 / \sigma_{\mathrm{CB}, 1}^{2}+1 / \sigma_{\varepsilon}^{2}\right) \neq \phi_{\text {fund }}^{O}$ [see (24)]. As a result, even if we disregard both sources of heterogeneous information, the fundamental equilibrium will be distinct from the additional one.

However, as shown in Appendix G, the level of welfare in the fundamental equilibrium converges to the respective level in the additional equilibrium when $\lambda \rightarrow 1$, for arbitrary but fixed levels of $\sigma_{i}^{2}$. This is highly plausible because for $\lambda \rightarrow 1$, the term proportional to $\pi^{2}$ in the social loss function, which captures the distortions arising because only some firms are attentive, vanishes. As a result, the central bank has output stabilization as its single objective when it decides on monetary policy. This single objective can always be achieved efficiently, irrespective of the value of $\phi^{O}$. To sum up, the potentially harmful consequences of decision opacity for welfare depend on our assumption that some firms are inattentive, but not on the existence of heterogeneous signals.

\section{CONCLUSIONS}

In this paper we have examined the costs and benefits of central bank transparency in the presence of heterogeneous information. We have shown that central banks should always publish the information underlying their decisions, because withholding this information may lead to additional equilibria with adverse consequences for the variance of output and inflation.

In addition, we have argued that central banks may not be able to affect the economy in the very short term because of long time lags between policy implementation and its impact on output and prices. Communication may be used as an alternative means of influencing these economic variables. On the positive side, communication reduces the distortions arising from heterogeneous information and can be used to stabilize output. On the negative side, communicating the central bank's private information may lead to a larger inflation variance. Overall, society will benefit from postdecision transparency if it puts sufficient emphasis on output stabilization.

Central bankers may have incentives to choose postdecision opacity even if transparency would be socially optimal. First, while central bankers are usually concerned with the level of inflation, they may not take into account the additional beneficial effects of transparency arising from the reduction of relative price distortions. Second, conservative central bankers, who place lower emphasis on output stabilization than society, may not fully internalize the socially desirable impact of transparency on output. 


\section{NOTES}

1. Morris and Shin (2008) ascribe this view to notable scholars and policy-makers such as Ben Bernanke, Alan Blinder, Michael Woodford, and Lars Svensson.

2. The significance of multiple equilibria for business cycle fluctuations has recently been studied by Barinci et al. (2006), Akay (2010), and Castelnuovo (2012), among others.

3 . Roughly speaking, decision transparency corresponds to economic transparency and postdecision transparency, is equivalent to operational transparency, in the taxonomy introduced by Geraats (2002).

4. In a seminal contribution, Cukierman and Meltzer (1986) show that central banks may benefit from ambiguous control procedures because ambiguity enables central banks to create positive inflation surprises when this is most valuable to them. Faust and Svensson (2001) extend their framework by distinguishing between transparency and control-error variance. They argue that transparency is generally desirable. The present paper differs from these contributions in several respects. For example, we consider heterogeneous information among price setters and the central bank. Moreover, we consider the possibility that the central bank observes part of the shock after it has chosen a monetary policy.

5. W uses the standard central-bank loss function, which takes into account costs arising from inflation and output variance but not from price differences due to heterogeneous signals.

6. By letting the variance of the demand shock go to infinity in the present paper, we obtain a uniform distribution on the line of real numbers as a special case. In this case the results in B are exactly identical to the ones obtained here. A detailed analysis is available upon request.

7. This framework is similar to the yeoman farmer model of price setting under monopolistic competition presented in Rotemberg and Woodford (1997).

8. We neglect the firm index for the optimal price $p^{*}$ because this price is identical for all firms.

9. The demand shocks are equivalent to the labor supply shocks in Adam (2007) because both types of shock do not affect the gap between equilibrium output and its socially optimal level.

10. For a recent application of the concept of sticky information, see Giuli (2010).

11. It would be equivalent to introduce sticky prices in the following manner. Suppose that all firms could freely choose their prices at the beginning of the period. Later, after additional information has become available, only a fraction $\lambda$ of firms could readjust their prices. The remaining firms would be stuck with the prices they had chosen at the beginning of the period.

12. Bernanke et al. (1999, pp. 315-320), state that the consensus estimate of the lag between policy actions and their main effect on inflation is about two years. Batini and Nelson (2001) confirm Friedman's findings on the basis of more recent U.S. and U.K. data.

13. Although it may also be possible for central banks to affect inflation over shorter horizons to some extent, this may require substantial variations in the instrument. Large changes in the instrument may be prohibitively costly, as they may destabilize financial markets. As a consequence, we make the simplifying assumption that the central bank is not able to affect inflation in the near future by its instrument.

14. Our assumption that it is socially optimal to stabilize prices at the previous period's price level is not restrictive. It could be justified by some small additional costs of inflation not captured in our model.

15. Allowing for $a_{\mathrm{CB}} \neq a_{\mathrm{SOC}}$ and $b_{\mathrm{CB}} \neq b_{\mathrm{SOC}}$ allows us to study conflicts of interests if these weights are different because of the delegation of monetary policy to a conservative central banker, for example.

16. This can be confirmed by observing that $\psi_{m}$ is identical for all attentive firms [see (12)].

17. See Judd (1985) and Uhlig (1996) for accounts of how a law of large numbers can be stated for a continuum of i.i.d. random variables. 
18. If $\phi^{O}=0$ held, the equilibrium would correspond to a pooling equilibrium. Although it is somewhat tedious, it is immediate to show that such an equilibrium cannot exist. Intuitively, because the normal distribution extends to the entire range of real numbers, the central bank's estimate of the shock can be arbitrarily large. For extremely large expected shocks, the central bank will always find it beneficial to deviate from $m=0$. Moreover, it is possible to show that a situation where firms believed that $\phi^{O}=0$ and the central bank always chose $m=0$ would lead to higher social losses compared to the fundamental equilibrium.

19. In the knife-edge case where the numerator on the right-hand side of (25) is zero [and thus $\phi_{\text {add }}^{O}=0$ in (25)], only one fixed point with $\phi^{O} \neq 0$ exists, namely $\phi_{\text {fund }}^{O}$. Note 18 explains in more detail why the case $\phi^{O}=0$ has to be excluded.

20. $\operatorname{Var}_{i \in[0, \lambda]} p_{i}=0$, which can be formally verified immediately, is a consequence of the fact that this term captures the losses caused by the heterogeneity of firms' signals. These signals are irrelevant for $\sigma_{\mathrm{CB}, 0}^{2} \rightarrow 0$, which entails $s_{\mathrm{CB}, 0}=\varepsilon$.

21. This point has the coordinates $(4 / 25,16 / 25)$.

22. For each value of $\phi^{O}$, a different efficient frontier obtains. Only for $\phi_{\text {fund }}^{O}$ and $\phi_{\text {add }}^{O}$ is the point chosen by the central bank on the efficient frontier consistent with the firms' beliefs.

23. In fact, if the central bank chose $m=\phi_{\text {fund }}^{O} s_{\mathrm{CB}, 0}$, although the firms believed it was pursuing $m=\phi_{\text {add }}^{O} s_{\mathrm{CB}, 0}$, the resulting combination of inflation and output variance would not even lie on the efficient frontier.

24. One can show that the delegation of monetary policy to a conservative central banker can reduce the potential losses caused by decision opacity (but it can never eliminate these losses). For an analysis of the impact of the degree of central bank conservatism under equilibrium indeterminacy when the equilibrium is selected by a sign restriction, see Castelnuovo (2012).

25. An alternative sufficient condition is $\lambda \leq 2 / 3$, which guarantees that the right-hand side of (27) is larger than one.

26. An additional Appendix on the relationship between the corollary and Proposition 1 in B is available upon request.

27. In Appendix A, we show that $\operatorname{Var}_{i \in[0,1]} p_{i}=\frac{1-\lambda}{\lambda} \pi^{2}+\lambda \operatorname{Var}_{i \in[0, \lambda]} p_{i}$.

\section{REFERENCES}

Adam, Klaus (2007) Optimal monetary policy with imperfect common knowledge. Journal of Monetary Economics 54, 267-301.

Akay, Koray (2010) Indeterminacy in cash-in-advance models and the role of frictions. Macroeconomic Dynamics 14, 119-135.

Angeletos, George-Marios and Alessandro Pavan (2007) Efficient use of information and social value of information. Econometrica 75, 1103-1142.

Baeriswyl, Romain (2007) Central Bank's Action and Communication. Munich discussion paper 2007-10.

Baeriswyl, Romain and Camille Cornand (2010) The signaling role of policy action. Journal of Monetary Economics 57, 682-695.

Barinci, Jean-Paul, Arnaud Chéron, and Francois Langot (2006) Liquidity constraints, heterogeneous households and sunspot fluctuations. Macroeconomic Dynamics 10, 529-544.

Batini, Nicoletta and Edward Nelson (2001) The lag from monetary policy actions to inflation: Friedman revisited. International Finance 4, 381-400.

Bernanke, Ben S., Thomas Laubach, Frederic S. Mishkin, and Adam S. Posen (1999) Inflation Targeting. Princeton, NJ: Princeton University Press.

Blinder, Alan S., Michael Ehrmann, Marcel Fratzscher, Jakob De Haan, and David-Jan Jansen (2008) Central bank communication and monetary policy: A survey of theory and evidence. Journal of Economic Literature 46, 910-945.

Branch, William A., John Carlson, George W. Evans, and Bruce McGough (2009) Monetary policy, endogenous inattention, and the volatility trade-off. Economic Journal 119, 123-157. 
Buiter, Willem H. (1999) Alice in Euroland. Journal of Common Market Studies 73, 181-209.

Castelnuovo, Efrem (2012) Policy switch and the Great Moderation: The role of equilibrium selection. Macroeconomic Dynamics 16, 449-471.

Cukierman, Alex and Allan H. Meltzer (1986) A theory of ambiguity, credibility, and inflation under discretion and asymmetric information. Econometrica 54, 1099-1128.

DeGroot, Morris H. (1970) Optimal Statistical Decisions. New York: McGraw-Hill.

Dincer, Nergiz and Barry Eichengreen (2010) Central bank transparency: Causes, consequences and updates. Theoretical Inquiries in Law 11, 73-124.

Faust, Jon and Lars E.O. Svensson (2001) Transparency and credibility: Monetary policy with unobservable goals. International Economic Review 42, 369-397.

Friedman, Milton (1972) Have monetary policies failed? American Economic Review Papers and Proceedings 62, 11-18.

Geraats, Petra M. (2002) Central bank transparency. Economic Journal 112, 532-565.

Gersbach, Hans and Volker Hahn (2007) Information content of wages and monetary policy. Journal of Money, Credit and Banking 39, 133-149.

Gersbach, Hans and Volker Hahn (2009) Voting transparency in a monetary union. Journal of Money, Credit and Banking 41, 809-830.

Giuli, Francesco (2010) Robust policies in a sticky information economy. Macroeconomic Dynamics $14,311-342$.

Goodfriend, Marvin (1986) Monetary mystique: Secrecy and central banking. Journal of Monetary Economics 17, 63-92.

Hahn, Volker (2002) Transparency in monetary policy: A survey. ifo Studien 48, 429-455.

Hellwig, Christian (2005) Heterogeneous Information and the Benefits of Transparency. Mimeo, UCLA.

Judd, Kenneth L. (1985) The law of large numbers with a continuum of IID random variables. Journal of Economic Theory 35, 19-25.

Mankiw, N. Gregory and Ricardo Reis (2002) Sticky information versus sticky prices: A proposal to replace the New Keynesian Phillips curve. Quarterly Journal of Economics 117, 12951328.

Morris, Stephen and Hyun Song Shin (2002) Social value of public information. American Economic Review 92, 1521-1534.

Morris, Stephen and Hyun Song Shin (2008) Coordinating expectations in monetary policy. In J.-P. Touffut (ed.), Central Banks as Economic Institutions, pp. 88-104. Northampton, MA: Edward Elgar.

Romer, David (2005) Advanced Macroeconomics. New York: McGraw-Hill.

Rotemberg, Julio J. and Michael Woodford (1997) An optimization-based econometric model for the evaluation of monetary policy. NBER Macroeconomics Annual 12, 297-346.

Sibert, Anne (2002) Monetary policy with uncertain central bank preferences. European Economic Review 46, 1093-1109.

Sibert, Anne (2003) Monetary policy committees: Individual and collective reputation. Review of Economic Studies 70, 649-665.

Sibert, Anne (2009) Is transparency about central bank plans desirable? Journal of the European Economic Association 7, 831-857.

Svensson, Lars E.O. (2006) Social value of public information: Comment: Morris and Shin (2002) is actually pro-transparency, not con. American Economic Review 96, 448-452.

Uhlig, Harald (1996) A law of large numbers for large economies. Economic Theory 8, 41-50.

Vickers, John (1986) Signalling in a model of monetary policy with incomplete information. Oxford Economic Papers 38, 443-455.

Walsh, Carl E. (2007) Optimal economic transparency. International Journal of Central Banking 3 , 5-36.

Woodford, Michael (2002) Inflation stabilization and welfare. Contributions to Macroeconomics 2. Available at http://www.bepress.com/bejm/contributions/vol2/iss1/art1. 


\section{APPENDIX A: DERIVATION OF (3)}

We have already mentioned that optimal monetary policy involves a minimization of a weighted average of the variance of prices and the variance of output. We apply this result and derive an expression for the variance of prices in the context of our model.

The prices of the firms in $[0, \lambda]$ can be written as the sum of a common and an idiosyncratic part, i.e.,

$$
p_{i}=\bar{p}+\mu_{i}
$$

where $\bar{p}$ is the average price of the firms in $[0, \lambda]$ and $\left(\mu_{i}\right)_{i=0}^{1}$ are the idiosyncratic components of $\left(p_{i}\right)_{i=0}^{1}$, which satisfy $\int_{0}^{\lambda} \mu_{i} d i=0$. Using the fact that the firms in $\left.] \lambda, 1\right]$ choose $p_{-1}=0$, which implies that $p=\lambda \bar{p}$ and thus $\bar{p}=p / \lambda$, (A.1) can be stated as

$$
\begin{aligned}
p_{i} & =\frac{p}{\lambda}+\mu_{i} \\
& =\frac{\pi}{\lambda}+\mu_{i} .
\end{aligned}
$$

Applying (A.2) and $\int_{0}^{\lambda} \mu_{i} d i=0$, the variance of prices in our model can be written as

$$
\begin{aligned}
\underset{i \in[0,1]}{\operatorname{Var}} p_{i} & =\int_{0}^{\lambda}\left(p_{i}-p\right)^{2} d i+\int_{\lambda}^{1} p^{2} d i \\
& =\int_{0}^{\lambda}\left(\frac{\pi}{\lambda}-p+\mu_{i}\right)^{2} d i+(1-\lambda) \pi^{2} \\
& =\int_{0}^{\lambda}\left(\frac{\pi}{\lambda}-\pi\right)^{2} d i+\int_{0}^{\lambda} \mu_{i}^{2} d i+(1-\lambda) \pi^{2} \\
& =\lambda\left(\frac{1}{\lambda}-1\right)^{2} \pi^{2}+\lambda \underset{i \in[0, \lambda]}{\operatorname{Var}} p_{i}+(1-\lambda) \pi^{2} \\
& =\frac{1-\lambda}{\lambda} \pi^{2}+\lambda \underset{i \in[0, \lambda]}{\operatorname{Var}} p_{i} .
\end{aligned}
$$

Hence, the social loss function can be stated as (3) with $b_{\text {SOC }}=\frac{\lambda^{2}}{1-\lambda}$. In principle, parameter $a_{\text {SOC }}$ could also be derived from the structural parameters of the underlying microeconomic model [see Adam (2007)].

Q.E.D

\section{APPENDIX B: DERIVATION OF $\Phi^{O}\left(\phi^{O}\right)$}

In this Appendix, we derive the optimal policy of the central bank under the assumptions that $s_{\mathrm{CB}, 0}$ is not disclosed directly and that the firms believe that the central bank chooses $m$ according to $m=\phi^{O} s_{\mathrm{CB}, 0}$ for some $\phi^{O} \neq 0$. Minimizing (5) subject to (2) and (22) results in the first-order condition:

$$
\mathbf{E}_{\mathrm{CB}, 0}\left[\lambda\left(\psi_{m}+\frac{\psi_{\mathrm{CB}, 0}}{\phi^{O}}\right) p+a_{\mathrm{CB}}\left(1-\lambda\left(\psi_{m}+\frac{\psi_{\mathrm{CB}, 0}}{\phi^{O}}\right)\right)(m-p+\varepsilon)\right]=0 .
$$


Rearranging terms yields

$$
\begin{aligned}
& \left\{\lambda\left(\psi_{m}+\frac{\psi_{\mathrm{CB}, 0}}{\phi^{O}}\right)-a_{\mathrm{CB}}\left[1-\lambda\left(\psi_{m}+\frac{\psi_{\mathrm{CB}, 0}}{\phi^{O}}\right)\right]\right\} \mathbf{E}_{\mathrm{CB}, 0}[p] \\
& +a_{\mathrm{CB}}\left[1-\lambda\left(\psi_{m}+\frac{\psi_{\mathrm{CB}, 0}}{\phi^{O}}\right)\right]\left(m+\mathbf{E}_{\mathrm{CB}, 0}[\varepsilon]\right)=0 .
\end{aligned}
$$

We observe that

$$
\mathbf{E}_{\mathrm{CB}, 0}[p]=\lambda\left(\psi_{m}+\psi_{\mathrm{CB}, 0} / \phi^{o}\right) m+\lambda\left[\left(\psi_{\mathrm{CB}, 1}+\psi_{i}\right) \hat{\gamma}_{\mathrm{CB}, 0}\right] s_{\mathrm{CB}, 0}
$$

must hold, which follows from (22), $\mathbf{E}_{\mathrm{CB}, 0}\left[s_{\mathrm{CB}, 1}\right]=\mathbf{E}_{\mathrm{CB}, 0}[\varepsilon]=\hat{\gamma}_{\mathrm{CB}, 0} s_{\mathrm{CB}, 0}$, and the fact that the firms believe the central bank's signal $s_{\mathrm{CB}, 0}$ to be $m / \phi^{O}$. It is now straightforward to show that inserting (B.2) and $\mathbf{E}_{\mathrm{CB}, 0}[\varepsilon]=\hat{\gamma}_{\mathrm{CB}, 0} s_{\mathrm{CB}, 0}$ into (B.1) yields $m=\Phi^{O}\left(\phi^{O}\right) s_{\mathrm{CB}, 0}$, where $\Phi^{O}\left(\phi^{O}\right)$ is given by (23).

Q.E.D.

\section{APPENDIX C: DERIVATION OF (24) AND (25)}

We have to find all solutions to the equation $\Phi^{O}\left(\phi^{O}\right)=\phi^{O}$ with $\phi^{O} \neq 0$. For this purpose, we note that

$$
\left(\psi_{i}+\psi_{\mathrm{CB}, 1}\right) \hat{\gamma}_{\mathrm{CB}, 0}=\psi_{\mathrm{CB}, 0}-\hat{\gamma}_{\mathrm{CB}, 0} \psi_{m},
$$

which can be readily verified from (7)-(9), (12)-(15), and (18). Inserting (C.1) into $\Phi^{O}\left(\phi^{O}\right)=\phi^{O}$, where $\Phi^{O}\left(\phi^{O}\right)$ is given by (23), and rearranging yields:

$$
\begin{aligned}
& \lambda^{2}\left(\psi_{m}+\frac{\psi_{\mathrm{CB}, 0}}{\phi^{O}}\right)^{2} \phi^{O}+a_{\mathrm{CB}}\left[1-\lambda\left(\psi_{m}+\frac{\psi_{\mathrm{CB}, 0}}{\phi^{O}}\right)\right]^{2} \phi^{O} \\
& =-\left\{\lambda^{2}\left(\psi_{\mathrm{CB}, 0}-\hat{\gamma}_{\mathrm{CB}, 0} \psi_{m}\right)\left(\psi_{m}+\frac{\psi_{\mathrm{CB}, 0}}{\phi^{O}}\right)\right. \\
& \left.\quad-a_{\mathrm{CB}}\left[\hat{\gamma}_{\mathrm{CB}, 0}-\lambda\left(\psi_{\mathrm{CB}, 0}-\hat{\gamma}_{\mathrm{CB}, 0} \psi_{m}\right)\right]\left[1-\lambda\left(\psi_{m}+\frac{\psi_{\mathrm{CB}, 0}}{\phi^{O}}\right)\right]\right\} .
\end{aligned}
$$

Multiplying through by $\phi^{O}$ yields a quadratic equation in $\phi^{O}$. It is tedious but straightforward to show that this equation has the solutions (24) and (25).

Q.E.D.

\section{APPENDIX D: PROOF OF PROPOSITION 2}

\section{D.1. THE EXPECTED VALUE OF $y^{2}$}

First we compare the expected value of $y^{2}$ under the fundamental equilibrium and under the additional equilibrium. In both cases it is given by 


$$
\begin{aligned}
\mathbf{E}\left[y^{2}\right]= & \mathbf{E}\left[(m-p+\varepsilon)^{2}\right] \\
= & \mathbf{E}\left[\left(\phi^{O} s_{\mathrm{CB}, 0}-\lambda\left(\left(\psi_{m} \phi^{O}+\psi_{\mathrm{CB}, 0}\right) s_{\mathrm{CB}, 0}+\psi_{\mathrm{CB}, 1} s_{\mathrm{CB}, 1}+\psi_{i} \varepsilon\right)+\varepsilon\right)^{2}\right] \\
= & \mathbf{E}\left[\left(\left(\phi^{O}\left(1-\lambda \psi_{m}\right)-\lambda \psi_{\mathrm{CB}, 0}\right) s_{\mathrm{CB}, 0}-\lambda \psi_{\mathrm{CB}, 1} s_{\mathrm{CB}, 1}+\left(1-\lambda \psi_{i}\right) \varepsilon\right)^{2}\right] \\
= & \left\{\left[\phi^{O}\left(1-\lambda \psi_{m}\right)-\lambda \psi_{\mathrm{CB}, 0}\right] s_{\mathrm{CB}, 0}-\lambda \psi_{\mathrm{CB}, 1} s_{\mathrm{CB}, 1}+\left(1-\lambda \psi_{i}\right) \varepsilon\right\}^{2} \sigma_{\varepsilon}^{2} \\
& +\left[\phi^{O}\left(1-\lambda \psi_{m}\right)-\lambda \psi_{\mathrm{CB}, 0}\right]^{2} \sigma_{\mathrm{CB}, 0}^{2}+\lambda^{2}\left(\psi_{\mathrm{CB}, 1}\right)^{2} \sigma_{\mathrm{CB}, 1}^{2},
\end{aligned}
$$

where the first line uses (2); the second uses (22); the third can be obtained be rearranging terms; and the fourth utilizes $\mathbf{E}\left[\varepsilon^{2}\right]=\mathbb{E}\left[\varepsilon \cdot s_{\mathrm{CB}, 0}\right]=\mathbf{E}\left[\varepsilon \cdot s_{\mathrm{CB}, 1}\right]=\sigma_{\varepsilon}^{2}, \mathbf{E}\left[s_{\mathrm{CB}, 0}^{2}\right]=\sigma_{\varepsilon}^{2}+\sigma_{\mathrm{CB}, 0}^{2}$, and $\mathbf{E}\left[s_{\mathrm{CB}, 1}^{2}\right]=\sigma_{\varepsilon}^{2}+\sigma_{\mathrm{CB}, 1}^{2}$. With the help of (12)-(15), it is laborious to calculate the difference between this expression for $\phi^{O}=\phi_{\text {add }}^{O}$ [see (25)] and $\phi^{O}=\phi_{\text {fund }}^{O}$ [see (24)] as

$$
\begin{aligned}
& \frac{\sigma_{\varepsilon}^{2} \gamma_{\mathrm{CB}, 0}(1-\lambda)^{2}}{\left[\lambda^{2} \alpha^{2}+a(1-\lambda)^{2}\right]^{2}\left(1-\gamma_{i}-\gamma_{\mathrm{CB}, 1}\right)[1-\lambda(1-\alpha)]^{2}\left[1-\lambda \gamma_{i}(1-\alpha)\right]^{2}} \\
& \quad \cdot\left\{[1-(1-\alpha) \lambda] \lambda\left[\alpha^{2} \lambda-a(1-\lambda)\right] \gamma_{i}\right. \\
& \left.\quad+\lambda \alpha[\lambda \alpha-a(1-\lambda)] \gamma_{\mathrm{CB}, 1}+a(1-\lambda)[1-(1-\alpha) \lambda]\right\}^{2} .
\end{aligned}
$$

Because this expression is always weakly positive, $\mathbf{E}\left[y^{2}\right]$ is always higher under an additional equilibrium over and against a fundamental equilibrium.

\section{D.2. THE EXPECTED VALUE OF $\pi^{2}+\frac{\lambda^{2}}{1-\lambda} \operatorname{Var}_{i \in[0, \lambda]} p_{i}$}

It is again straightforward but extremely tedious to compute the difference between $\pi^{2}+\frac{\lambda^{2}}{1-\lambda} \operatorname{Var}_{i \in[0, \lambda]} p_{i}$ for an additional equilibrium and the respective equilibrium under a fundamental equilibrium. For this reason, we simply give the respective expression:

$$
\begin{aligned}
& \frac{\left\{\lambda \alpha\left[\lambda \alpha-a_{\mathrm{CB}}(1-\lambda)\right] \gamma_{\mathrm{CB}, 1}+[1-(1-\alpha) \lambda]\left[\lambda^{2} \gamma_{i} \alpha^{2}+a_{\mathrm{CB}}(1-\lambda)\left(1-\lambda \gamma_{i}\right)\right]\right\}^{2}}{\left[a_{\mathrm{CB}}(1-\lambda)^{2}+\lambda^{2} \alpha^{2}\right]^{2}\left(1-\gamma_{i}-\gamma_{\mathrm{CB}, 1}\right)[1-(1-\alpha) \lambda]^{2}\left[1-\lambda \gamma_{i}(1-\alpha)\right]^{2}} \\
& \cdot \lambda^{2} \alpha^{2} \gamma_{\mathrm{CB}, 0} \sigma_{\varepsilon}^{2} .
\end{aligned}
$$

This expression is always weakly positive. Hence expected social losses are higher under the additional equilibrium than under the fundamental equilibrium.

Q.E.D.

\section{APPENDIX E: PROOF OF PROPOSITION 3}

In line with the law of large numbers, $\operatorname{Var}_{i \in[0, \lambda]} p_{i}$ can be written as

$$
\operatorname{Var}_{i \in[0, \lambda]} p_{i}=\lambda\left(\psi_{i}\right)^{2} \sigma_{i}^{2}
$$

Inserting (15) yields

$$
\operatorname{Var}_{i \in[0, \lambda]} p_{i}=\lambda \frac{\alpha^{2} \gamma_{i}^{2}}{\left[1-\gamma_{i} \lambda(1-\alpha)\right]^{2}} \sigma_{i}^{2} .
$$


As this is a monotonically increasing function of $\gamma_{i}$, and $\gamma_{i}$ is a monotonically increasing function of $\sigma_{\mathrm{CB}, 1}^{2}$, this establishes the first part of the proposition.

To show the second part of the proposition, we evaluate the impact of a marginal change in $\sigma_{\mathrm{CB}, 1}^{2}$ on $\mathbf{E}\left[\pi^{2}\right]=\mathbf{E}\left[p^{2}\right]$. For this purpose, we derive an expression for $\mathbf{E}\left[\pi^{2}\right]$ in equilibrium. This can be achieved by combining (12)-(16). However, as the respective calculations are rather lengthy, we simply give the solution here:

$$
\begin{aligned}
& \mathbf{E}\left[\pi^{2}\right]=\frac{\left\{\left[1-\lambda-\lambda\left(1-\lambda+\alpha^{2} \lambda\right) \gamma_{i}\right] \gamma_{\mathrm{CB}, 1}+\gamma_{i}[1-\lambda(1-\alpha)]^{2}\left(1-\lambda \gamma_{i}\right)\right\}}{\left[1-\lambda \gamma_{i}(1-\alpha)\right]^{2}[1-\lambda(1-\alpha)]^{2}} \\
& \quad \frac{\left(1-\hat{\gamma}_{\mathrm{CB}, 0}\right) \lambda^{2} \alpha^{2} \sigma_{\varepsilon}^{2}}{1-\lambda} .
\end{aligned}
$$

Using (7)-(9) and (18), we can form the derivative of (E.3) with respect to $\sigma_{\mathrm{CB}, 1}^{2}$ :

$$
\frac{d \mathbf{E}\left[\pi^{2}\right]}{d \sigma_{\mathrm{CB}, 1}^{2}}=-\frac{\lambda^{2} \alpha^{2} \gamma_{\mathrm{CB}, 1}^{2}\left(3 \lambda \gamma_{i} \alpha+1-3 \lambda \gamma_{i}+2 \gamma_{i}\right)}{\left[1-\lambda \gamma_{i}(1-\alpha)\right]^{3}[1-\lambda(1-\alpha)]^{2}}
$$

We note that the numerator is strictly positive for all admissible parameter values. Consequently, (E.4) is negative, which entails the second part of the proposition.

Q.E.D.

\section{APPENDIX F: PROOF OF PROPOSITION 4}

Using (2) and (12)-(16) it is possible to compute

$$
\mathbf{E}\left[y^{2}\right]=\frac{\left(1-\hat{\gamma}_{\mathrm{CB}, 0}\right)\left\{\frac{\lambda \alpha \gamma_{\mathrm{CB}, 1}\left[\lambda(-2 \lambda+2 \lambda \alpha+2-\alpha) \gamma_{i}+2 \lambda-\lambda \alpha-2\right]}{(1-\lambda(1-\alpha))^{2}}+\left(1-\lambda \gamma_{i}\right)^{2}\right\}}{\left[1-\lambda \gamma_{i}(1-\alpha)\right]^{2}} \sigma_{\varepsilon}^{2} .
$$

With the help of (7)-(9) and (18), the derivative of (F.1) with respect to $\sigma_{\mathrm{CB}, 1}^{2}$ can be stated as

$$
\frac{d \mathbf{E}\left[y^{2}\right]}{d \sigma_{\mathrm{CB}, 1}^{2}}=\frac{\lambda \gamma_{\mathrm{CB}, 1}^{2} \alpha\left\{2(1-\lambda)+\lambda \alpha-\lambda \gamma_{i}[2(1-\lambda)+\lambda \alpha(1+\alpha)]\right\}}{\left[1-\lambda \gamma_{i}(1-\alpha)\right]^{3}[1-\lambda(1-\alpha)]^{2}} .
$$

This expression is strictly positive if and only if

$$
2(1-\lambda)+\lambda \alpha-\lambda \gamma_{i}[2(1-\lambda)+\lambda \alpha(1+\alpha)]>0
$$

or, equivalently,

$$
\gamma_{i}<\frac{1}{\lambda} \cdot \frac{2(1-\lambda)+\lambda \alpha}{2(1-\lambda)+\lambda \alpha(1+\alpha)}
$$

Together with $\gamma_{i}<\left[1 / \sigma_{i}^{2}\right] /\left[1 / \sigma_{\mathrm{CB}, 0}^{2}+1 / \sigma_{i}^{2}+1 / \sigma_{\varepsilon}^{2}\right]$, this establishes the claim of the proposition.

Q.E.D. 


\section{APPENDIX G: THE ROLE OF INATTENTIVENESS IN OUR FINDINGS ABOUT DECISION TRANSPARENCY}

In this Appendix, we show that social losses in the additional equilibrium converge to the losses in the fundamental one if $\lambda \rightarrow 1$ or, equivalently, all firms become attentive. The difference in the expected values of $y^{2}$ has been derived in Appendix D.1. As the numerator of this expression is proportional to $(1-\lambda)^{2}$ and the denominator converges to a finite value for $\lambda \rightarrow 1$, the difference in the expected values of $y^{2}$ is zero if all firms are attentive.

Before proceeding with our analysis of the role of inattentiveness, we note that we have implicitly multiplied the terms in the social loss function that capture distortions from price differences by $\lambda /(1-\lambda)$ in order to get rid of the factor $(1-\lambda) / \lambda$ before the term $\pi^{2} \cdot{ }^{27}$ This normalization is innocuous for a fixed level of $\lambda$. However, when taking the limit $\lambda \rightarrow 1$, we have to be careful to reintroduce this factor by multiplying the expressions for the expected value of $\pi^{2}+\frac{\lambda^{2}}{1-\lambda} \operatorname{Var}_{i \in[0, \lambda]} p_{i}$ that we have derived so far by $(1-\lambda) / \lambda$. The difference in the expected values of $\pi^{2}+\frac{\lambda^{2}}{1-\lambda} \operatorname{Var}_{i \in[0, \lambda]} p_{i}$ between the two equilibria is stated in Appendix D.2. This term, multiplied by $(1-\lambda) / \lambda$, vanishes for $\lambda \rightarrow 1$. This establishes the claim that the fundamental and the additional equilibrium involve identical levels of welfare for $\lambda \rightarrow 1$.

Q.E.D. 